\title{
Corrigendum: MicroRNA122 is a key regulator of $\alpha$-fetoprotein expression and influences the aggressiveness of hepatocellular carcinoma
}

\author{
Kentaro Kojima, Akemi Takata, Charles Vadnais, Motoyuki Otsuka, Takeshi Yoshikawa, Masao Akanuma, \\ Yuji Kondo, Young Jun Kang, Takahiro Kishikawa, Naoya Kato, Zhifang Xie, Weiping J. Zhang, \\ Haruhiko Yoshida, Masao Omata, Alain Nepveu \& Kazuhiko Koike
}

Nature Communications 2:338 doi: 10.1038/ncomms1345 (2011); Published 7 Jun 2011; Updated 25 Sep 2012.

This Article contains errors in the numbering of several papers in the reference list; reference 34 is incorrectly listed as reference 44 and references 35 to 44 are incorrectly listed as 34 to 43 . The correct numbering is as follows.

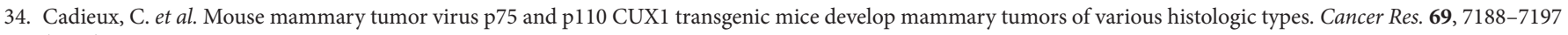
(2009).

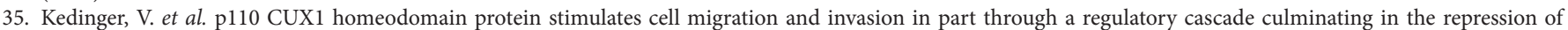
E-cadherin and occludin. J. Biol. Chem. 284, 27701-27711 (2009).

36. Michl, P. et al. CUTL1 is a target of TGF(beta) signaling that enhances cancer cell motility and invasiveness. Cancer Cell 7, 521-532 (2005).

37. Aleksic, T. et al. CUTL1 promotes tumor cell migration by decreasing proteasome-mediated Src degradation. Oncogene 26, 5939-5949 (2007).

38. Kunath, T. et al. Transgenic RNA interference in ES cell-derived embryos recapitulates a genetic null phenotype. Nat. Biotechnol. 21, 559-561 (2003).

39. Shouval, D. et al. Tumorigenicity in nude mice of a human hepatoma cell line containing hepatitis B virus DNA. Cancer Res. 41, 1342-1350 (1981).

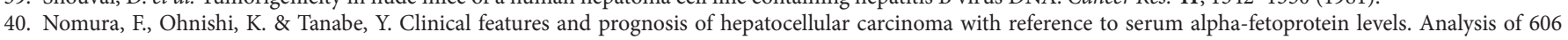
patients. Cancer 64, 1700-1707 (1989).

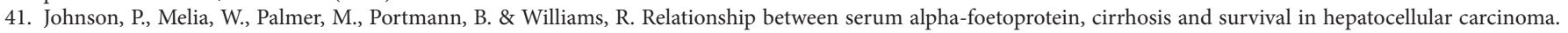
Br. J. Cancer 44, 502-505 (1981).

42. Xu, H. et al. Liver-enriched transcription factors regulate microRNA-122 that targets CUTL1 during liver development. Hepatology 52, 1431-1442 (2010).

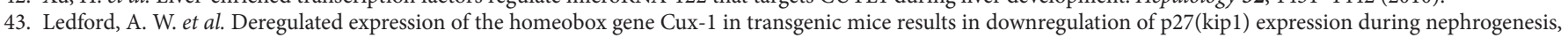
glomerular abnormalities, and multiorgan hyperplasia. Dev. Biol. 245, 157-171 (2002).

44. Brantley, J. G., Sharma, M., Alcalay, N. I. \& Heuvel, G. B. Cux-1 transgenic mice develop glomerulosclerosis and interstitial fibrosis. Kidney Int. 63, 1240-1248 (2003). 